\title{
The Uncertainty of the Surgical Margin in the Treatment of Low Grade Fibromyxoid Sarcoma: a Case Report and Literature Review
}

\author{
Sosnowska Patrycja ${ }^{1}$ (D) Agnieszka Turowska ${ }^{2} \cdot$ Nogal Piotr $^{3} \cdot$ Mańkowski Przemysław $^{1}$
}

Received: 9 April 2020 / Accepted: 30 April 2020 / Published online: 15 May 2020

(C) The Author(s) 2020

\begin{abstract}
Low grade fibromyxoid sarcoma (LGFMS) is a rare soft tissue tumor appearing mainly in young adults. Despite its bland histological features, the tumor has a tendency toward late local recurrence and distant metastases even up to 45 years after the diagnosis. The treatment of choice in this type of neoplasm is a radical surgical excision with clear resection margins. We decided to present a case report of a 17-year-old patient with LGFMS of the right hip. Surgical resection of the tumor was performed, but in the histopathological examination was described the minimal resection margin $(0.3 \mathrm{~mm})$. The multi-specialist team composed of oncologist, radiologist, and pediatric surgeon based on the literature decided to widen the resection margin despite its obtainment during the primary operation. The scar after the first surgery and surrounding soft tissues with the bigger margin were resected. No evidence of cancerous infiltration was found in the second histopathological material. Patient has stayed under the routine control of pediatric surgeon, pediatric oncologist, and has not presented recurrence for 3 years. In conclusion, when the resection margin is uncertain after the primary surgery, the increase of the range of operation allows the prevention of the late recurrence of the disease.
\end{abstract}

Keywords Child $\cdot$ Pediatric oncology $\cdot$ Pediatric surgery $\cdot$ Sarcoma $\cdot$ Soft tissue tumors

\section{Introduction}

Low grade fibromyxoid sarcoma (LGFMS, Evan's tumor) is a rare soft tissue tumor, usually described in adolescents and young adults. Low extremities and trunk wall are typical locations for this type of tumor [1-3]. Surgical resection is a recommended method of treatment [2-4]. In cases of nonradical excision, this type of tumors can recur, even after a long period of time [3]. We present a case of a patient treated due to this disease.

Sosnowska Patrycja

sosnowska@ump.edu.pl; patrycja.sosnowska@ outlook.com

1 Department of Pediatric Surgery, Traumatology and Urology, Poznan University of Medical Sciences, Szpitalna Street 27/33, 60-572 Poznan, Poland

2 Student Scientific Group: Pediatric Surgery, Department of Pediatric Surgery, Traumatology and Urology, Poznan University of Medical Sciences, Szpitalna Street 27/33, 60-572 Poznan, Poland

3 Department of Otolaryngology, Head and Neck Surgery, Poznan University of Medical Sciences, Przybyszewskiego Street 49, 60-355 Poznan, Poland

\section{Case Report}

A 17-year-old girl was admitted to the Department of Pediatric Surgery in Poznan due to tumor located nearby the right hip.

In the physical examination, the change was large, displaceable, soft, and painless. No enlarged lymph nodes were palpable.

Ultrasound examination revealed a solid lesion $(13.5 \times$ $12 \times 6.7 \mathrm{~cm}$ in size) with the moderate blood flow registered with Doppler USG. Magnetic resonance imaging excluded the infiltration of surrounding anatomical structures (Figs. 1, 2).

Surgical resection of the tumor was performed. In the histopathological examination, the minimal resection margin $(0.3 \mathrm{~mm})$ was described. The diagnostic revealed the FUS gene (16p11) rearrangements (FUS-DDIT3), which in correlation with the microscopic examination and the clinical data lead to the final diagnosis of low grade fibromyxoid sarcoma.

The decision about further proceeding was difficult for all participants of multi-specialist team. Finally, the minimal margin was not considered a safe for a patient, and decision about reoperation was made. The scar and the soft tissues with the bigger $2 \mathrm{~cm}$ margin were removed. No evidence of cancerous infiltration was found in the resected material. Patient has 


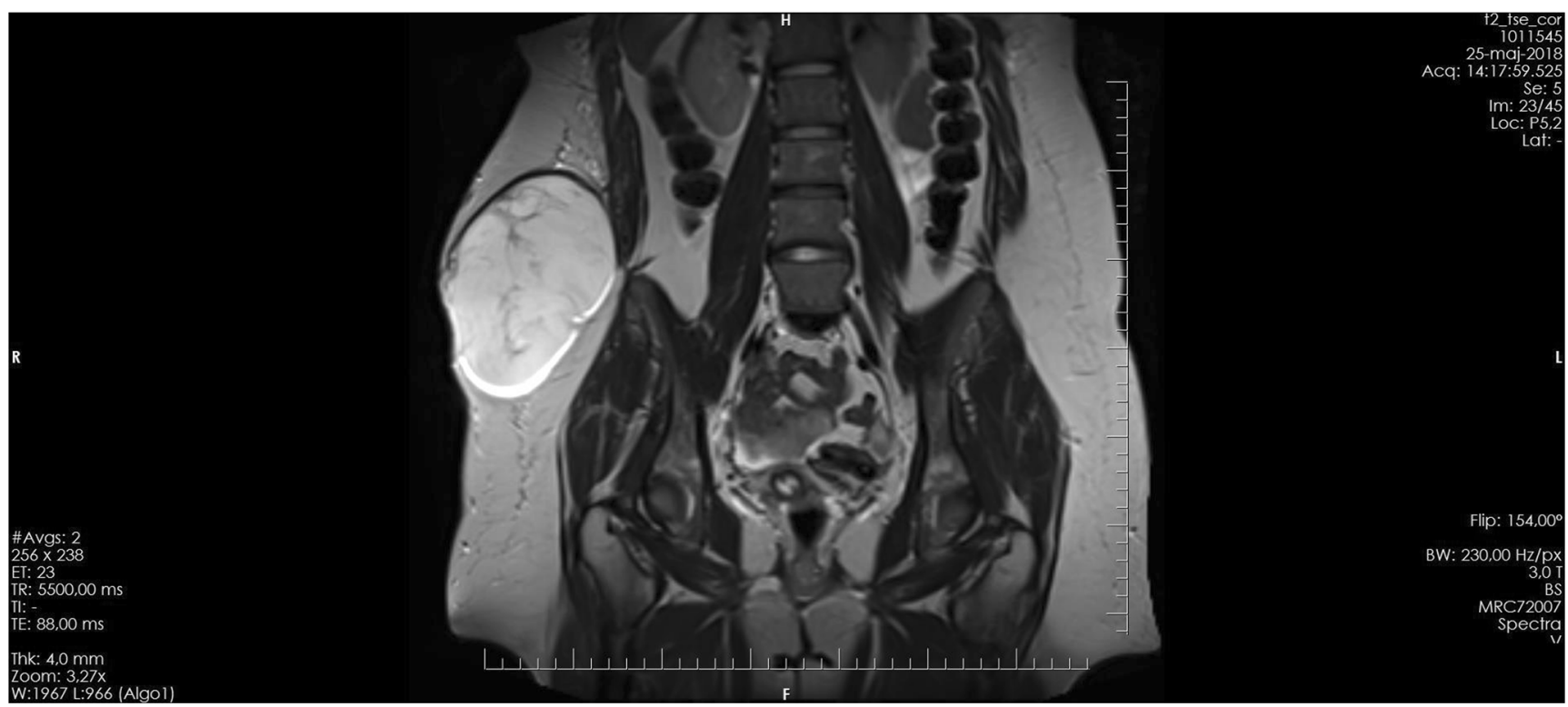

Fig. 1 Magnetic resonance image of the pelvis with the right hip tumor (frontal plane)

stayed under the routine control and has not presented recurrence for 3 years.

\section{Discussion}

Low grade fibromyxoid sarcoma is a benign tumor with the high potency of local recurrence $[2,5]$. The metastases of the lesion are rare, with the lungs, pleura, and chest wall as typical location. [1]. The metastatic process was excluded in our patient.

Despite its bland histological features, LGMFS has a tendency toward late local recurrence and distant metastases. The largest review of 273 cases was published by Tang [2]. The follow-up data was available for 186 patients. It revealed local recurrence rate of $29 \%$ and metastases rate of $18 \%$. MarettyNielsen et al. [3] presented similar results in their study. This is probably due to the fact that all of the cases that they presented where initially diagnosed as sarcomas which resulted in aggressive surgery. In many clinical studies regarding LGFMS, the majority of included cases were initially classified as benign tumors. Their classification as LGFMS was made retrospectively because of unexplained metastases. Moreover, many studies reported cases with follow-up shorter than 1 year. Meanwhile, previous studies reveal that local recurrence may occur 17 years [3] after primary surgery, while metastases may

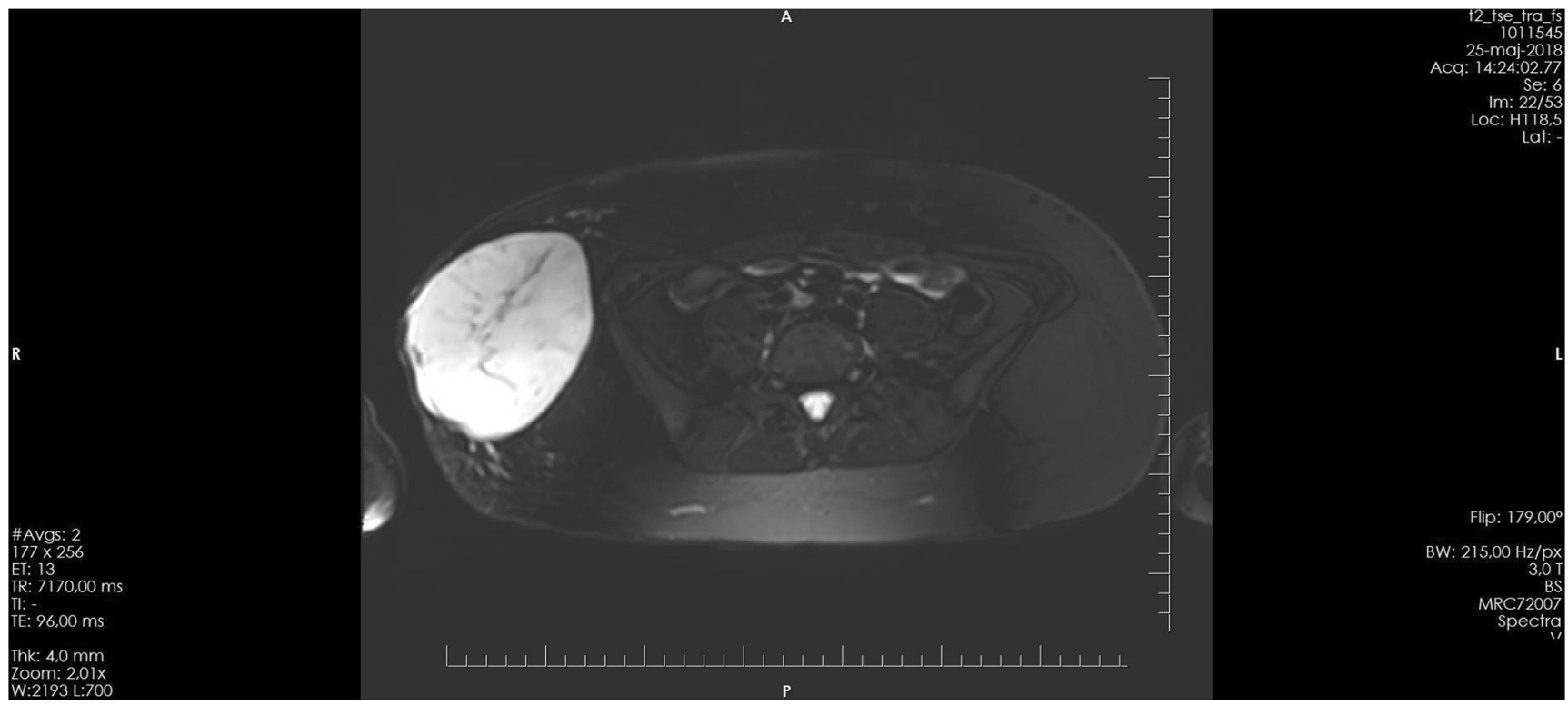

Fig. 2 Magnetic resonance imaging of the pelvis in the transverse plane 
appear up to 45 years later [1]. This indicates the necessity of long-term follow-up in case of this tumor.

Due to its paradoxically aggressive behavior, surgical excision with clear resection margins is the first line treatment for LGFMS. According to Enneking [6], classification margins are classified as marginal if the incision is made through the pseudocapsule, or as wide if there is a cuff of normal tissue around the tumor. In a previously mentioned clinical study of 14 patients published by Maretty-Nielsen et al. [3], the surgical margins were wide in 4 cases and marginal in 8 cases. Their study indicates that local recurrence occurred only in the cases in which surgery with marginal margins was performed. In the latest study on this subject published in 2018 by Sambri et al. [4], the importance of complete surgical resection is emphasized as well. Abe et al. in 2012 [7] presented a case study of an elderly patient with LGFMS on the forehead. Patient underwent an operation with $1 \mathrm{~cm}$ skin margin, which resulted in local recurrence after 15 months. Additional resection with $2 \mathrm{~cm}$ margin was performed, and there is no evidence of a disease after 1 year of follow up. Another case of recurring LGFMS was reported by Sakaguchi in 2016 [8]. An 8 -year-old boy underwent a surgery, but due to the unclear margins, the wide re-excision with $1 \mathrm{~cm}$ margin was performed after 2 months. There is no evidence of recurrence or metastases after 1 year follow-up.

The review of the literature confirms that in the case of an excision with uncertain margin, wide re-excision is advised in order to avoid late recurrence of a disease.

\section{Conclusion}

To conclude, LGFMS is an uncommon disease. In this publication, we would like to point out the importance of the radical excision with wide margins in prevention of the late recurrence of the disease.

Authors' Contributions This publication was approved by all co-authors. Conceptualization: Patrycja Sosnowska, Agnieszka Turowska

Methodology: Patrycja Sosnowska, Agnieszka Turowska

Formal analysis and investigation: Patrycja Sosnowska, Piotr Nogal

Writing original draft preparation: Agnieszka Turowska, Patrycja

Sosnowska, Piotr Nogal

Writing - review and editing: Przemysław Mańkowski

Data availability Not applicable.

\section{Compliance with Ethical Standards}

Conflict of Interest All authors declare that they have no conflict of interest.
Research Involving Human Participants and/or Animals Statement of human rights: All procedures performed in studies involving human participants were in accordance with the ethical standards of the institutional and/or national research committee and with the 1964 Helsinki declaration and its later amendments or comparable ethical standards.

Informed Consent For this type of study formal consent is not required.

Code Availability Not applicable.

Open Access This article is licensed under a Creative Commons Attribution 4.0 International License, which permits use, sharing, adaptation, distribution and reproduction in any medium or format, as long as you give appropriate credit to the original author(s) and the source, provide a link to the Creative Commons licence, and indicate if changes were made. The images or other third party material in this article are included in the article's Creative Commons licence, unless indicated otherwise in a credit line to the material. If material is not included in the article's Creative Commons licence and your intended use is not permitted by statutory regulation or exceeds the permitted use, you will need to obtain permission directly from the copyright holder. To view a copy of this licence, visit http://creativecommons.org/licenses/by/4.0/.

\section{References}

1. Evans HL (2011) Low-grade fibromyxoid sarcoma: a clinicopathologic study of 33 cases with long-term follow-up. Am J Surg Pathol 35(10):1450-1462

2. Tang Z, Hua ZZ, Tang LVC et al (2010) Low-grade Fibromyxoid sarcoma: clinical study and case report. J Oral Maxillofac Surg 68(4): 873-884

3. Maretty-Nielsen K, Baerentzen S, Keller J, Dyrop HB, Safwat A (2013) Low-grade fibromyxoid sarcoma: incidence, treatment strategy of metastases, and clinical significance of the FUS gene. Sarcoma 2013:1-6

4. Sambri A, Righi A, Tuzzato G, Donati D, Bianchi G (2018) Lowgrade Fobromyxoid sarcoma of the extremities: a clinicopathologic study of 24 cases and review of the literature. Polish J Pathol 69(3): 219-225

5. Lee EJ, Hwang HJ, Byeon HK et al (2015) A low grade fibromyxoid sarcoma originating from the masseter muscle: a case report. J Med Case Rep 9(1):1-5

6. Enneking WF, Spanier SS, Goodman MA (2003) A system for the surgical staging of musculoskeletal sarcoma. 1980. Clin Orthop Relat Res 415:4-18

7. Abe Y, Hashimoto I, Nakanishi H (2012) Recurring facial low-grade fibromyxoid sarcoma in an elderly patient: a case report. J Med Investig 59(3-4):266-269

8. Sakaguchi T, Hamada Y, Nakamura Y, Shirai T, Hamada H, Kon M (2016) Low-grade fibromyxoid sarcoma of the abdominal wall in an 8-year-old boy. J Pediatr Surg Case Reports 15(2016):1-4

Publisher's Note Springer Nature remains neutral with regard to jurisdictional claims in published maps and institutional affiliations. 